\title{
Cazando animales en el bestiario cosmológico: el cocodrilo en el suroeste de Colombia y en regiones vecinas del Ecuador (800 A.C. a 500 D.C.)
}

La chasse aux animaux dans le bestiaire cosmologique: le crocodile dans le Sudouest de la Colombie et les régions voisines de l'Équateur (800 av JC-500 ap. JC) Hunting the beasts of the cosmological bestiary: the crocodile in southwestern Colombia and neighbouring regions of Ecuador (800 B.C. to A.D. 500)

Marianne Cardale de Schrimpff

\section{OpenEdition}

Journals

Edición electrónica

URL: http://journals.openedition.org/bifea/3948

DOI: $10.4000 /$ bifea.3948

ISSN: 2076-5827

Editor

Institut Français d'Études Andines

Edición impresa

Fecha de publicación: 1 diciembre 2006

Paginación: 409-431

ISSN: 0303-7495

Referencia electrónica

Marianne Cardale de Schrimpff, « Cazando animales en el bestiario cosmológico: el cocodrilo en el suroeste de Colombia y en regiones vecinas del Ecuador (800 A.C. a 500 D.C.) », Bulletin de I'Institut français d'études andines [En línea], 35 (3) | 2006, Publicado el 01 junio 2006, consultado el 01 diciembre 2020. URL : http://journals.openedition.org/bifea/3948 ; DOI : https://doi.org/10.4000/bifea. 3948

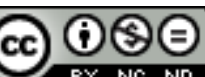

Les contenus du Bulletin de l'Institut français d'études andines sont mis à disposition selon les termes de la licence Creative Commons Attribution - Pas d'Utilisation Commerciale - Pas de Modification 4.0 International. 


\title{
Cazando animales en el bestiario cosmológico: el cocodrilo en el suroeste de Colombia y en regiones vecinas del Ecuador (800 A.C. a 500 D.C.)
}

\author{
Marianne Cardale de Schrimpff
}

\begin{abstract}
Resumen
Aunque las sociedades del suroeste de Colombia compartían una tradición tecnológica y cosmológica, durante este período, con muchos elementos que se extendían a ambos lados de la actual frontera colombo-ecuatoriana, las investigaciones sobre aspectos puntuales de esta tradición siguen siendo relativamente escasas. Aquí se examina un aspecto de la cosmología: el papel del cocodrilo en las culturas de la Costa Pacífica, especialmente las de Tumaco-La Tolita y otras ubicadas más al sur. Luego se sigue la pista a representaciones de este animal en culturas andinas como llama y San Agustín, afuera de su hábitat natural.
\end{abstract}

Palabras clave: cocodrilo, cosmología precolombina, Colombia, Ecuador

La chasse aux animaux dans le bestiaire cosmologique : le crocodile dans le Sud-ouest de la Colombie et les régions voisines de l'Équateur (800 av JC-500 ap. JC)

\section{Résumé}

Les sociétés complexes du SO de la Colombie préhispanique ont partagé des traditions technologiques et cosmologiques communes dont de nombreux éléments s'étendaient aussi dans la partie située au sud de l'actuelle frontière entre la Colombie et l'Équateur. Mais les études ponctuelles sur cette tradition demeurent encore assez rares. Cet article s'intéresse à un aspect de la cosmologie : le rôle du 
crocodile dans la culture Tumaco-La Tolita sur la côte Pacifique et dans les régions situées plus au sud. Il s'intéresse ensuite aux représentations de cet animal dans des régions comme llama et San Agustín, situées hors de l’habitat naturel de cet animal.

Mots clés : crocodile, cosmologie précolombienne, Colombie, Équateur

\title{
Hunting the beasts of the cosmological bestiary: the crocodile in southwestern Colombia and neighbouring regions of Ecuador (800 B.C. to A.D. 500)
}

\begin{abstract}
Although, during this period, societies of southwestern Colombia shared a common tradition in technology and belief systems, elements of which extended to neighbouring regions of Ecuador, studies of detailed aspects of this tradition are still fairly scarce. The crocodile, represented in pottery, gold and other materials, is found in cultures on the Pacific coast, particularly Tumaco-La Tolita, and can be followed into regions outside its natural habitat in Andean cultures such as Ilama and San Agustin. It is suggested that this animal had an important role in the cosmology of the region.
\end{abstract}

Key words: crocodile, pre-Columbian cosmology, Colombia, Ecuador

\section{INTRODUCCIÓN}

Desde las investigaciones de Pérez de Barradas hace más de cincuenta años se reconoce que, durante un periodo largo, las sociedades del suroeste de Colombia compartían una tradición tecnológica y cosmológica (fig. 1). Durante buena parte del último milenio antes del nacimiento de Cristo y la mitad del milenio siguiente, muchos elementos de esta tradición se extendían a ambos lados de la actual frontera colombo-ecuatoriana. Sin embargo, las investigaciones sobre elementos puntuales de estas tradiciones siguen siendo escasas. En el suroccidente de Colombia las representaciones de animales, ejecutadas en cerámica, oro, piedra y otros materiales, son relativamente frecuentes y han sido estudiadas en detalle por Anne Legast (p.e. 1991; 1993; 1995; 1998) y Edgar Emilio Rodríguez (1992) con una contribución importante de Cadena \& Bouchard (1980). La importancia cosmológica del felino, del murciélago y de la serpiente se expresa en representaciones individuales o combinadas en un ser compuesto o «fabuloso» (Cardale de Schrimpff, 1989).

últimamente, nuevos hallazgos y análisis del material existente han resaltado la importancia de otros animales. Esta investigación fue concebida, inicialmente, como complemento de otra proyectada por Ann Legast, ambas dirigidas a detectar la importancia de especies particulares de animales dentro de la cosmología del suroccidente. Una de estas especies, el perro de monte (Potos flavus), había sido identificada hace varios años por Cadena \& Bouchard (1980: 54-55) en la cerámica de La Tolita-Tumaco pero solo hasta hace poco empieza a apreciarse su gran importancia en otras culturas contemporáneas (Bray et al., 2005: 189-191, figs. IV.63-IV.65). Desafortunadamente, la oportunidad para profundizar en el estudio de este animal no se presentó y, en la presente ocasión, nos quedamos solamente con la otra especie o, mejor dicho, familia, que planeamos investigar, los Crocodylia.

Recordemos la enorme importancia que tenía el cocodrilo en el Horizonte Temprano de Perú, en la cosmología de Chavín, mientras que en Mesoamérica fue uno de los carnívoros más 


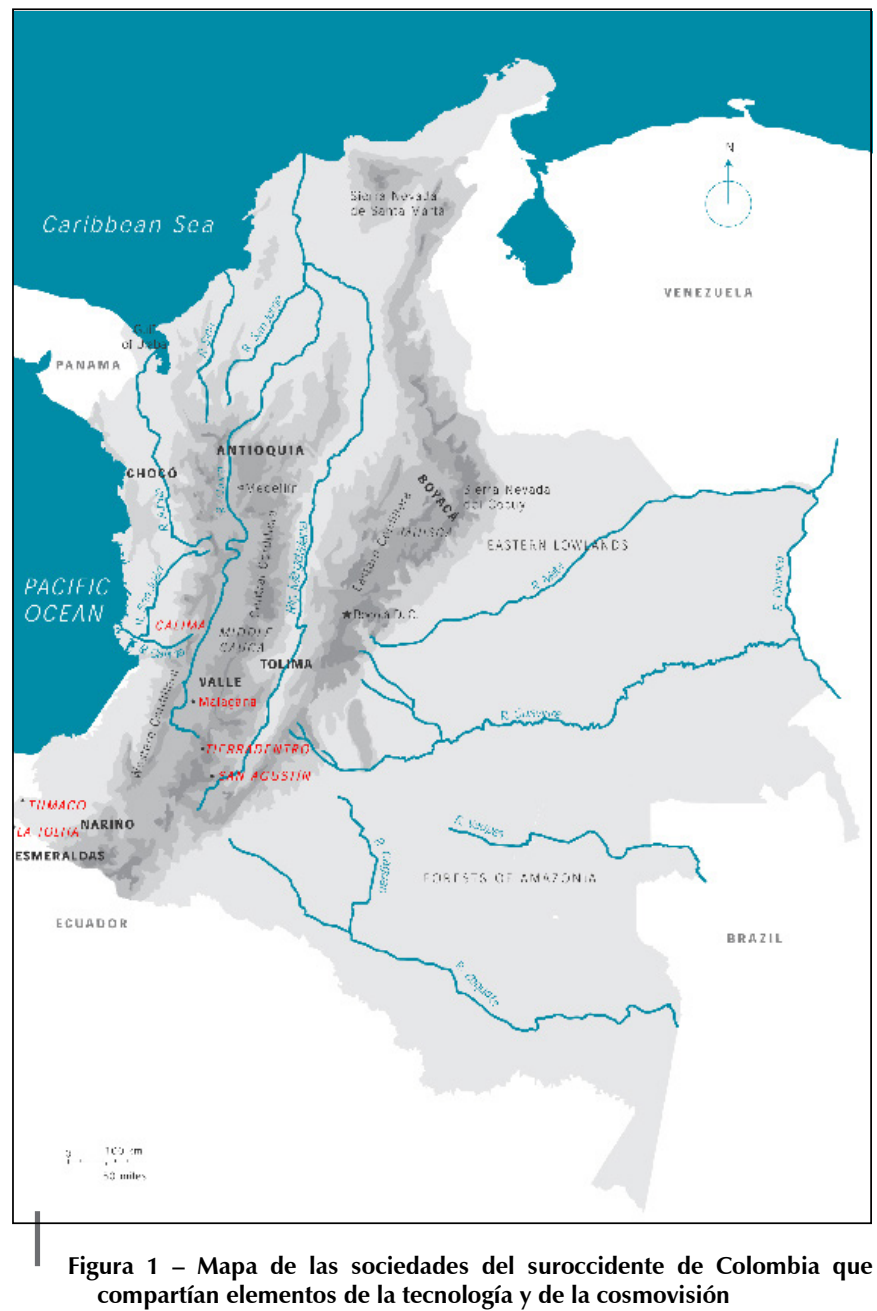

venerados. Entre los mayas el caimán era un dios creador anciano y, posiblemente, el principal de su panteón. Por su entorno acuático, su gran tamaño y su dorso espinoso, este animal era un metáfora común por la tierra (Miller \& Taube, 1997: 46) con las montañas de esta concebidas como flotando sobre el mar en la misma manera en que el cocodrilo flota sobre el agua. Aquí se examina el papel del cocodrilo y su posible contenido simbólico en una región relativamente reducida del área intermedia. Estos reptiles no recibieron mayor mención en los estudios iniciales de Legast o en el mío propio sobre la representación compuesta por varios animales que llamé el Ser Fabuloso (Cardale de Schrimpff, 1989) y solo en estudios recientes (Legast, 1998; Cardale de Schrimpff, 2005) se empieza a detectar su importancia real.

Aunque es un concepto de aceptación generalizada que en el arte precolombino nada es meramente decorativo, que todo tiene su significado social o cosmológico, es solo con un estudio minucioso de cada uno de sus aspectos que podemos aspirar a decodificar los iconos y así comprender algo más de una cosmología y sistema de creencias muy diferente al nuestro. Una de las dificultades que encontramos con la identificación de los animales que conforman 
el bestiario cosmológico, es que presupone un conocimiento detallado del animal. Aunque la mayoría de los arqueólogos somos capaces de reconocerlo en representaciones que muestran el animal completo y en forma naturalista, desconocemos muchos detalles importantes de su aspecto y de su comportamiento; nos queda aun más difícil saber cuáles de estos detalles eran los más importantes para las poblaciones precolombinas¹. Por estas razones podemos estar casi seguros de que muchas piezas precolombinas ocultan referencias a animales - tanto cocodrilos como numerosas otras especies- que no hemos sido capaces de reconocer todavía.

\section{LOS CROCODYLIA DEL SUROCCIDENTE DE COLOMBIA}

En Colombia se han identificado cuatro géneros de crocodylia con un total de siete especies, dos de las cuales son endémicas en el suroccidente del país (Medem, 1953: 7; 1981; 1983). Estas son el Crocodylus acutus de la familia Crocodylidae y la babilla (Caiman cocodrilus) 2 de la familia Alligatoridae. Se presta para confusión el hecho de que el cocodrilo (Crocodylus acutus) en el idioma diario o popular en Colombia se denomina «caimán» mientras que en el Ecuador, este nombre se utiliza para lo que en Colombia se conoce como «babilla». El C. acutus se encuentra por toda la costa Pacífica donde habita tanto los ríos y ciénagas de agua dulce como los manglares, puesto que también tolera el agua salobre. Habría sido muy común en el periodo La Tolita-Tumaco y sin duda hubiera sido el miembro más grande de la familia conocido por los habitantes de la región en aquella época. Los animales adultos miden entre 4 y 7 metros de largo (Medem, 1981: 145) y por su abundancia y habilidad de esconderse en las aguas y los manglares frecuentados por la gente, hubiera presentado un peligro mucho mayor que el jaguar o la serpiente. Su grado de agresividad varía (Medem, 1981: 156) pero cuando los primeros españoles subieron por el río Magdalena desde la costa Caribe, tenían tanto temor de estos animales que, al ir al río a recoger agua, la hacían con una totuma amarrada al extremo de un palo largo para evitar acercarse mucho a la orilla (Simón, 1981 [1627])3. Estos cocodrilos no solo arrebataban sus víctimas desde la orilla sino que, en ocasiones, atacaban las canoas en medio del río, matando y comiendo a sus ocupantes (Medem, 1981: 156)).

El otro miembro endémico de esta familia en el suroccidente es la babilla; aunque la babilla es mucho más pequeña que el Crocodylus acutus, se han reportado ejemplares de hasta 2,5 m de largo (Medem 1981: 66 ss.). Entre los varios detalles físicos que la diferencian del caimán está la arista interocular que le da su nombre en inglés the spectacled caiman (caimán de anteojos). No parece tener una reputación de agresividad, salvo cuando la hembra cuida su nido con huevos. Los hábitats de las dos especies son, hasta cierto punto, excluyentes. Si los unos ocupan los ríos grandes, los otros buscan las ciénagas y pantanos donde están más protegidos, puesto que las babillas figuran en la lista de las presas preferidas de los cocodrilos (Medem, 1981: 156). La cola de ambas especies proporciona una carne blanca, de buen sabor: en el sitio arqueológico de Momil, a orillas del río Sinú cerca de la costa Caribe, hace un poco más de dos mil años los huesos y placas óseas tanto del caimán como de la babilla, eran tan frecuentes que no parece haber duda que formaban parte de la dieta en aquel periodo (Medem, 1981: 106); también se encuentran sus restos en varios sitios de la misma época en el Ecuador (Gutiérrez, 2002). Sin embargo, entre algunos grupos etnográficos actuales la actitud hacia su utilización como carne es ambivalente: para los grupos tukanos del Vaupés esta carne es apreciada pero, a la vez, peligrosa

1 La literatura etnográfica abunda en referencias a diseños cuyo significado le sería casi imposible reconocer a una persona que no conoce determinada cultura a fondo. Un ejemplo son los diseños tejidos en la urdimbre de las faldas de las mujeres Bari, que representan culebras de diferentes especies, pero que pasan casi desapercibidos para el ojo forastero (Cardale de Schrimpff, 1984: fig. 80).

2 Antes denominado Caiman sclerops chiapasus.

3 Parte 2nda, Primera Noticia Historial, Cap. XXVI; edición de 1981: 117. 
puesto que el cocodrilo es un predador igual que el hombre y generalmente el hombre no se come a otros predadores 4 .

Las representaciones precolombinas, generalmente, no muestran suficientes detalles para indicar la especie - si es que se quería mostrar la especie como tal en vez de un conjunto de rasgos característicos de diferentes miembros de la familia (p.e. Legast, 1998: 11)—. Por esta razón en este artículo se utiliza el término cocodrilo para toda representación, a no ser que algún ejemplar en particular muestre indicios claros de que se trata de una babilla.

\section{LAS REPRESENTACIONES DE CROCODYLIA EN LA COSTA PACÍFICA}

Seguramente no es accidental que sea entre los antiguos pobladores de la Costa Pacífica, especialmente los de la cultura Tumaco-La Tolita, donde las representaciones de cocodrilos son más numerosas, pues vivían en un hábitat óptimo para estos animales. Aunque los orígenes de la cultura Tumaco-La Tolita se encuentran en Chorrera, en la cultura material de esta última las representaciones de cocodrilos no son comunes y menos en las culturas de Valdivia y Machalilla 5 . En Chorrera, a pesar de su gran reputación por la riqueza y variedad de las representaciones de animales, uno de los pocos ejemplares detectados es una pequeña pieza en cerámica ilustrada por Lathrap (1995: 47, fig. 65), modelada en forma de la cabeza de un cocodrilo. Este autor interpreta la pieza como un tubo para inhalar rapé alucinógeno. Gutiérrez (2002: 72) reseña dos ejemplos adicionales con representaciones de cocodrilo sobre objetos que él considera de uso ritual.

En Tumaco-La Tolita, en cambio, encontramos una verdadera explosión de representaciones de cocodrilo. Las hay en una gran variedad de objetos elaborados en cerámica: figurinas, partes o adornos de vasijas, mangos de recipientes, cuentas de collar, pintaderas y ralladores (fig. 2). También se encuentran en hueso o cacho de venado figurinas con cocodrilos (Brezzi, 2003: fig. 593).

Las figurinas o figurillas de esta cultura han sido descritas por un buen número de investigadores desde Raoul d'Harcourt (1947), incluyendo a Bouchard \& Mora (1988), Brezzi (2003), Sánchez (1981) y Ramírez (2003). Aunque la mayoría de estos estudios se concentran en las figurinas antropomorfas, muchos contienen algunas ilustraciones de cocodrilos y las publicaciones de Cadena \& Bouchard (1980) y Rodríguez (1992) se enfocan específicamente en la identificación de animales. En muchas de estas representaciones el nivel del detalle es tal que sugiere que el artista tenía en mente una especie particular, el cocodrilo o la babilla. Se pueden dividir la representaciones en tres grupos:

- representaciones naturalistas

- un hombre-cocodrilo o tal vez un hombre con máscara de cocodrilo

- figuras antro-zoomorfas donde la figura humana termina en la cabeza de un cocodrilo.

Entre las representaciones naturalistas encontramos figurinas con el animal completo como las ilustradas por Rodríguez (1992: figs. 28, 29)6 e interpretadas por él como de babilla (Caiman sclerops chiapasus $)^{7}$ por algunas características como «... los palpebrales bien elevados, el hocico relativamente corto y ancho y la nariz curva hacia arriba...» (Rodríguez 1992: 45). Se encuentra, también, modelado sobre partes de vasijas como el mango de un recipiente (fig. 2. 1) y el

4 Stephen Hugh-Jones, comunicación personal 2006. Reichel-Dolmatoff (1996: 188) tiene una descripción interesante del proceso de ahumar la carne de ejemplares juveniles del Caiman sclerops y, después, prensarla entre tablas de madera para guardarla en canastos forrados con hojas que, si se colocan en un ambiente con mucho humo, permite su conservación hasta tres meses.

5 Examinamos la hipótesis de Andrés Gutiérrez (2002: 69) en las Conclusiones.

6 MBP T0266 y T6612; el T-2502 presenta la particularidad de tener las placas óseas representadas en forma circular.

7 Ver nota 1. 
Figura 2 - El cocodrilo en Tumaco-La Tolita

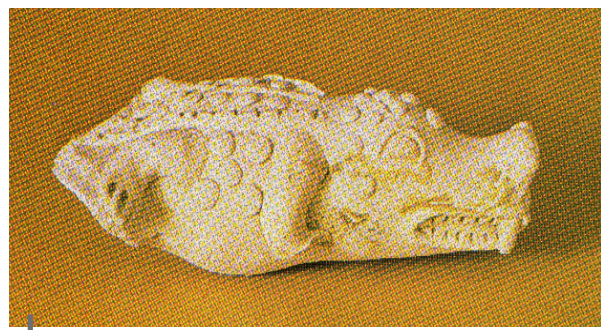

Figura 2. 1 - Mango de un recipiente; el hocico relativamente corto $y$ ancho sugiere que el animal representado es una babilla

Procedencia indeterminada. L. $18 \mathrm{~cm}$. MBP T2502. Fondo de Promoción de la Cultura, Museo Arqueologico MUSA

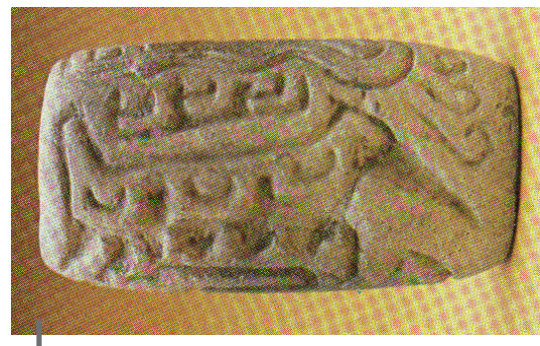

Figura 2. 3 - Pintadera cilíndrica sobre la cual se reconoce el largo hocico del cocodrilo representado en perfil y terminado en su nariz característica

Procedencia indeterminada. L. $6,5 \mathrm{~cm}$. MBP T-2252. Fondo de Promoción de la Cultura, Museo Arqueologico MUSA

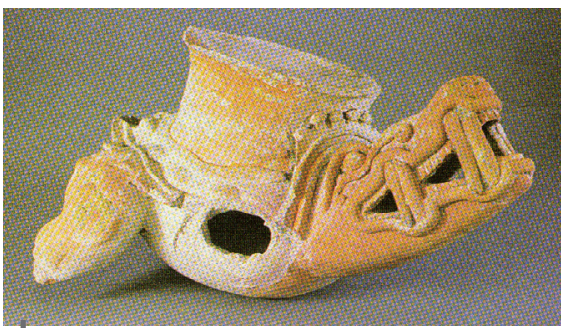

Figura 2. 2 - El hocico agudo y la elevación preocular indicaría la representación de un cocodrilo de la especie Crocodylus acutus

Procedencia indeterminada. Alt. 21,3 cm. MBP T-10704. Fondo de Promoción de la Cultura, Museo Arqueologico MUSA

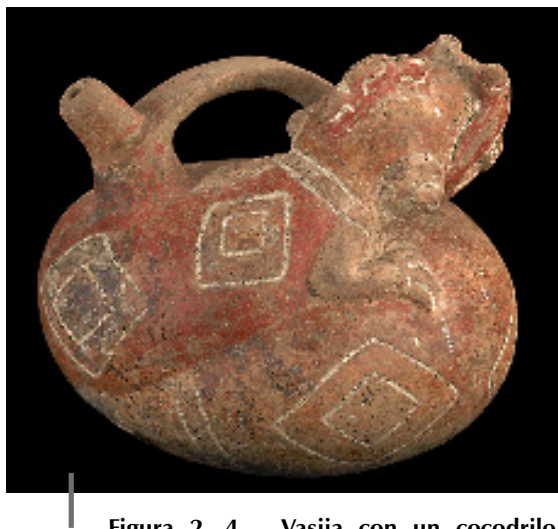

Figura 2. 4 - Vasija con un cocodrilo modelado encima

Procedencia indeterminada. Altura: 15,30 x 16,60 cm. MO C-13510. Colección Museo del Oro, Banco de la República, Bogotá, Colombia Fotografía: Clark Manuel Rodríguez

fragmento de una pieza de cerámica con varias cabezas de babilla (Cadena \& Bouchard, 1980: fig. II, 5)8, ambas en el Museo Casa Marqués de San Jorge.

Por otro lado, en el concepto de Rodríguez (1992: 45), el caimán, Crocodylus acutus, parece ser representado por un soporte zoomorfo conservado en el mismo museo (fig. 2. 2). En esta especie la cabeza es más larga y angosta y tiene una elevación preocular pronunciada que se aprecia bien en la figura. En adición, «la notoriedad de los dientes mandibular $4^{\circ}$ y maxilar $5^{\circ}$ 
relativamente bien separados...» también es característico de este especie. Otra cabeza sola, al parecer de caimán, se encuentra en el Museo del Banco Central en Quito9 (Valdéz, 1992: fig. 193). En los ralladores, un medio donde se representa una gran variedad de animales, tampoco falta el cocodrilo (p.e. Brezzi, 2003: fig. 25) pero, en este caso, sin elementos que faciliten la identificación de la especie.

Entre los adornos personales, se reconoce la cabeza del caimán en cuentas de collar, y d'Harcourt (1947: Planche LX, 13) ilustra un ejemplar muy fino en cerámica, encontrado en Muisne, sobre la costa Ecuatoriana en la boca del río del mismo nombre. La cuenta es tubular, de $6 \mathrm{~cm}$ de largo, con la cabeza del animal modelada sobre el eje largo. El Museo Casa Marqués de San Jorge tiene una pintadera cilíndrica sobre la cual se puede identificar el largo hocico del cocodrilo, representado de perfil y terminado en su nariz característica10 (fig. 2. 3). Tanto esta pieza como la de la fig. 2. 4 tienen la cabeza adornada con una hilera de incisiones angulares conformando una especie de cresta; el origen de este parece comprenderse al observar la ilustración de la cabeza de un cocodrilo en la fig. 311, donde se aprecian las placas óseas sobre la cabeza y nuca del animal, y la fig. 2.1 donde el artista precolombino representa las mismas placas en forma relativamente natural. Aquí propongo que es en estas donde hay que buscar el origen de las crestas muy elaboradas, con volutas, que ostentan algunos animales de Tumaco-La Tolita y de sociedades más al sur.

Un ejemplar del segundo grupo, el hombre-cocodrilo o, tal vez, hombre con máscara de cocodrilo, está ilustrado en Rodríguez (1992: fig. 30)12.

El tercer grupo, las figuras humanas que terminan en cabeza de cocodrilo (fig. 4.1) son de un interés especial puesto que este mismo motivo se encuentra en otros lugares del suroccidente colombiano reflejando, indudablemente, un concepto cosmológico compartido. Ilustraciones de ejemplares Tumaco-La Tolita de por lo menos ocho museos y colecciones en Colombia, Ecuador y otras partes del mundo, han sido publicadas por varios autores (cuadro 1)13. Ha sido necesario trabajar con fotos y no con las piezas originales, con la desventaja de que las reproducciones no siempre son de óptima calidad y generalmente se tomaron desde un solo ángulo; muchos detalles del cocodrilo se ven mejor de perfil pero otros, como los rasgos de la figura humana, se aprecian solamente en una toma frontal. El artículo escrito por el zoólogo Alberto Cadena y el arqueólogo Jean-François Bouchard (1980: 52, lam. II, 1

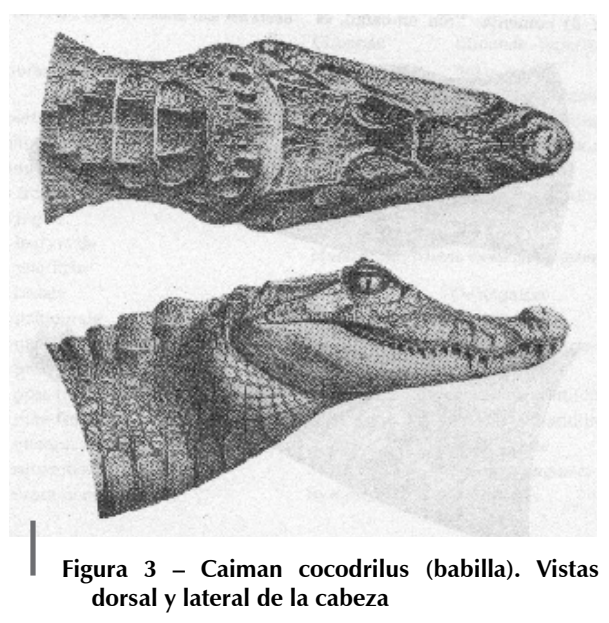

Según Natterer (1841) (tomado de Medem, 1983: fig. 27) -4) incluye cuatro fotografías de estas piezas. Por detalles como la forma del hocico (más corto y menos angosto que el del cocodrilo), los autores identifican el animal como una babilla (Caiman crocodilus chiapasus). Las piezas son relativamente grandes, la mayoría entre 10 y $15 \mathrm{~cm}$ de largo. Aunque las que se conservaron son, generalmente, de cerámica, se conoce un ejemplar

9 De Pampa de Oro, La Tolita. M.B.C.Q. $n^{\circ}$ 4-39-80.

10 Esta figura ha sido publicada por Bouchard \& Mora (1988: Fig. 36 y p. 70) quienes la interpretan como una serpiente

11 En este caso el dibujo es de una babilla pero los caimanes también tienen placas óseas en esta parte del cuerpo.

12 M.B.P. T 10075 , sin procedencia.

13 Los ejemplares analizados aquí son, seguramente, solo una pequeña muestra de los que existen así que no se hace el intento de cuantificar los diferentes atributos pues con una muestra tan pequeña, no tiene sentido. 
Marianne Cardale de Schrimpff

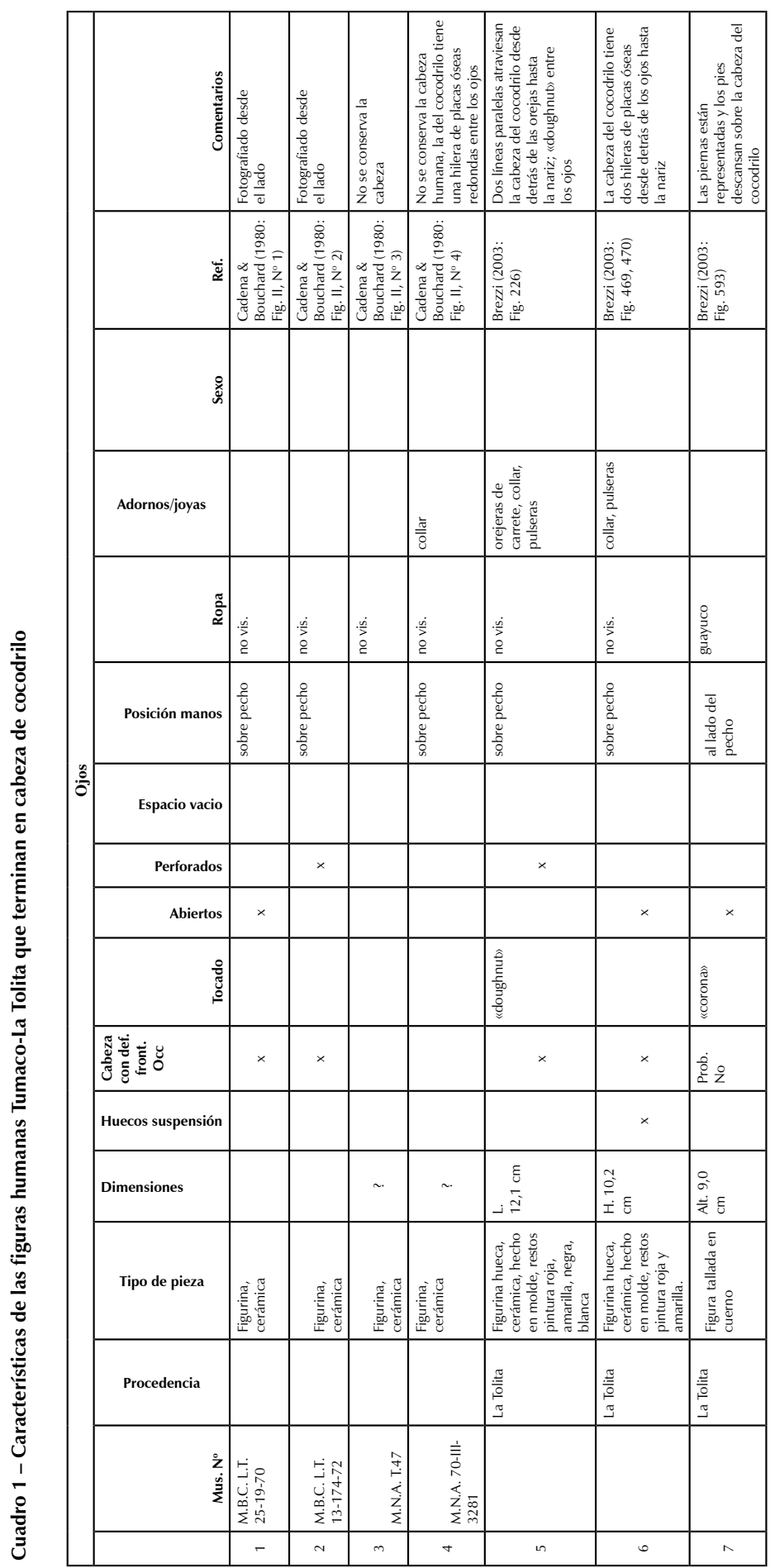


EL cocodrilo en el suroeste de Colombia y regiones vecinas del Ecuador (800 a. C. a 500 d. C.)

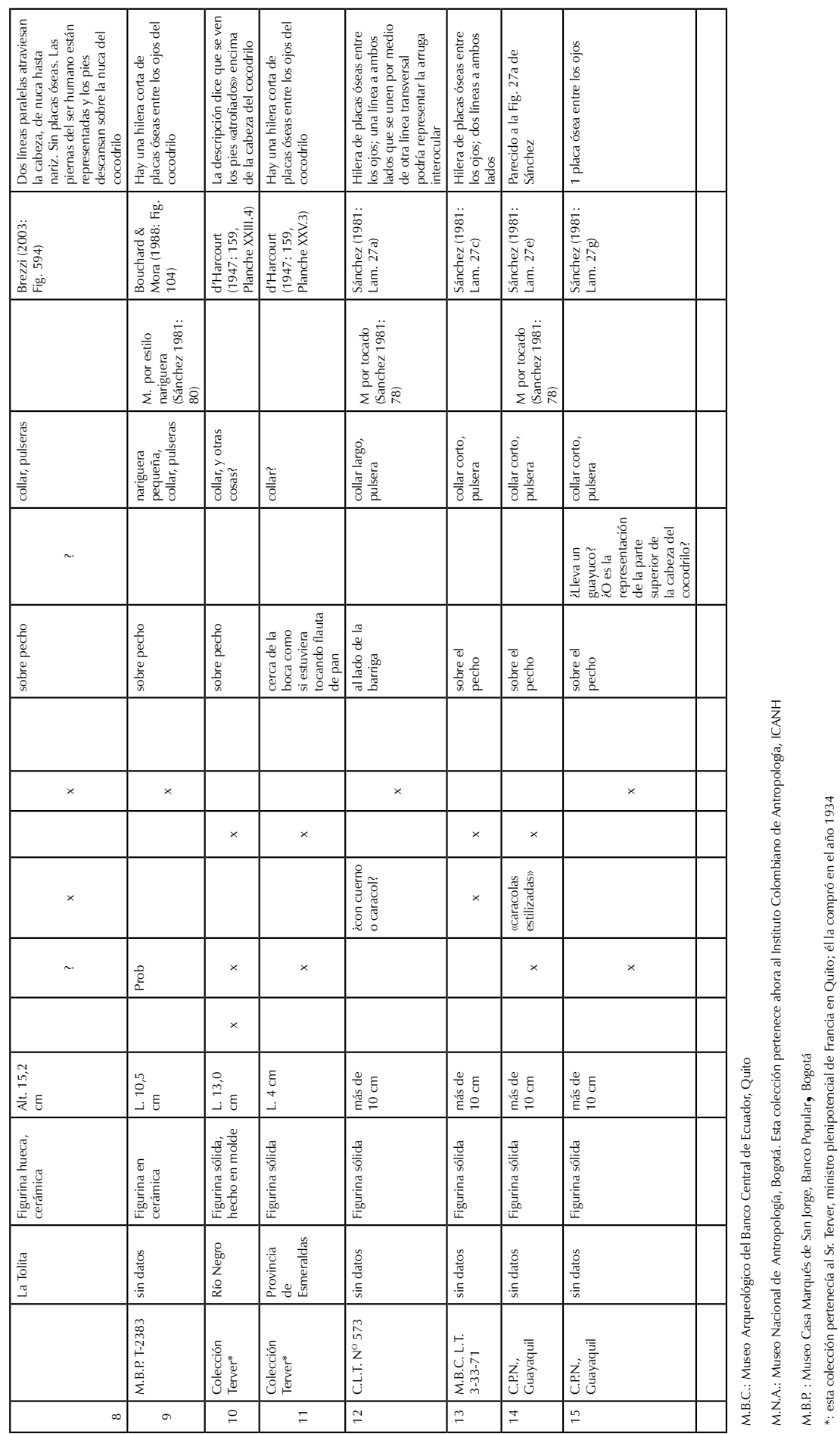


tallado en cacho de venado o hueso (Brezzi, 2003: fig. 593). Las de cerámica pueden ser sólidas o huecas, la mayoría hechas en molde ${ }^{14}$.

Aunque a primera vista, este grupo de piezas parece relativamente homogéneo, cuando se examinan en detalle se encuentra cierta variedad. Las cabezas de los cocodrilos varían aunque, por los inconvenientes expresados arriba, no siempre se pueden apreciar todos los detalles de importancia. En muchas de ellas se representan las placas óseas por medio de una o dos hileras de protuberancias pequeñas en el espacio entre los ojos; a veces las hileras se extienden hasta la nariz. La forma de estas protuberancias es semi-rectangular o redonda, aunque en un ejemplar (Sánchez, 1981: lam. 27e) ellas tienen una depresión central en forma de rosquilla (en la naturaleza las escamas del cocodrilo varían de forma, rectangular o redonda, según la parte del cuerpo que cubren). A veces las protuberancias están acompañadas por una línea a cada lado. En algunos pocos ejemplares, estas se unen inmediatamente debajo del ojo tal vez para indicar, en forma muy estilizada, la arruga interocular característica de la babilla. En otras ocasiones (p.e. Brezzi, 2003: fig. 594) las líneas se encuentran solas, sin representaciones de placas óseas.

La parte humana de estas figuras antropozoomorfas también varía bastante. Con frecuencia la cabeza presenta los rasgos típicos de muchas figurinas Tumaco, con el cráneo modificado artificialmente para darle una forma alta, inclinada, y abultada hacia atrás (p.e. Bouchard \& Mora, 1988: fig. 104). En las figurinas de esta cultura el cabello rara vez aparece y tal vez fue cubierto con una especie de gorro. Varias de las figuras humanas lucen tocados más complejos, con adornos (Sánchez, 1981: lam. 27c) que pueden tener forma de cuerno (?) o caracola (?) (Sánchez, 1981: lam. 27a, e). El ejemplar tallado en cacho lleva una especie de diadema o corona. Los ojos también varían —en nuestra pequeña muestra siete tienen forma almendrada, abierta, contra seis con una perforación central- . Por lo menos una figura ostenta orejeras de carrete. Usualmente la figura lleva un collar y pulseras (indicadas por varias líneas paralelas en ambas muñecas). Por lo general, los collares son cortos y, hasta donde se alcanza a apreciar, formados por un dije central grande bordeado por una o más hileras de cuentas tubulares perforadas sobre el eje largo (p.e. Bouchard \& Mora, 1988: fig. 104). En otras figuras el collar tiene dos dijes (Sánchez, 1981: lam. 27c) o es un collar largo que llega cerca al ombligo (Sánchez, 1981: lam. 27a).

Los brazos casi siempre se representan formando un ángulo recto, con las manos sobre el pecho, una posición no muy común en las figurinas de esta cultura. Si se muestran de pie, generalmente tienen los brazos estirados a los lados del cuerpo y las palmas de las manos vueltas hacia abajo o hacia delante; otras tienen el brazo alzado, como saludando (Sánchez, 1981: 38-42). Como en las figuras del hombre-cocodrilo rara vez se representa la parte inferior del cuerpo, no es ninguna sorpresa que, en la muestra analizada aquí, solo una pieza tenga indicaciones de ropa. De las figurinas de otras clases se sabe que los hombres utilizaban un guayuco corto, suspendido por un cinturón relativamente ancho y las mujeres una falda apretada, muy decorada, que llegaba hasta alrededor de las rodillas (Sánchez, 1981: 74-5; Ramírez, 2003: 136). Como la temperatura media durante el día en la Costa Pacífica es alrededor de $30^{\circ} \mathrm{C}$, parece que en la vida diaria, la gente acostumbraba andar con el torso desnudo, cubriendo esta parte del cuerpo para ceremonias y fiestas. Esta parquedad de ropa nos priva de una de las indicaciones más seguras del sexo de las figuras, puesto que ninguna tiene indicios físicos claros. La única figura con ropa lleva un guayuco (Brezzi, 2003: fig. 593)15. Sin embargo, existen otras pistas. Emma Sánchez (1981: 74-82) ha logrado distinguir ciertos tocados y adornos que son exclusivos de hombres o de mujeres y, en tres ejemplares de nuestra muestra (cuadro 1), estos atributos sugieren que las figuras son masculinas.

\footnotetext{
14 No hay datos para todas.

15 Su fig. 594 también muestra una figura de cuerpo entero pero en la foto no se alcanza a distinguir bien si la figura lleva ropa.
} 


\section{Figura 4 - El hombre-caimán}

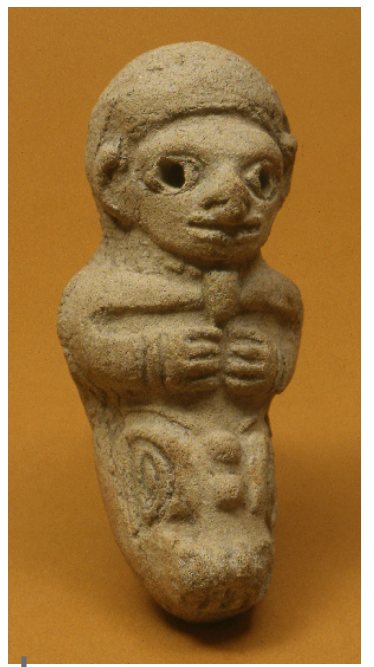

Figura 4. 1 - Figura humana La TolitaTumaco que termina en cabeza de cocodrilo

Procedencia indeterminada. L. 10,5 cm. MBP T-2383. Fondo de Promoción de la Cultura, Museo Arqueológico MUSA

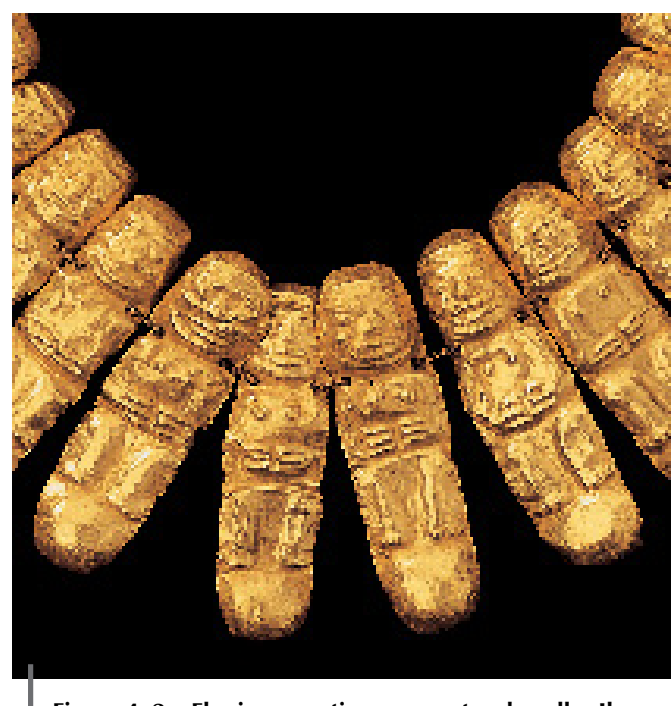

Figura 4. 2 - El mismo motivo en cuentas de collar Ilama Procedencia: Restrepo. L. promedio de las cuentas: 5,9 cm. MO 29270. Colección Museo del Oro, Banco de la República, Bogotá, Colombia. Fotografía: Rudolf

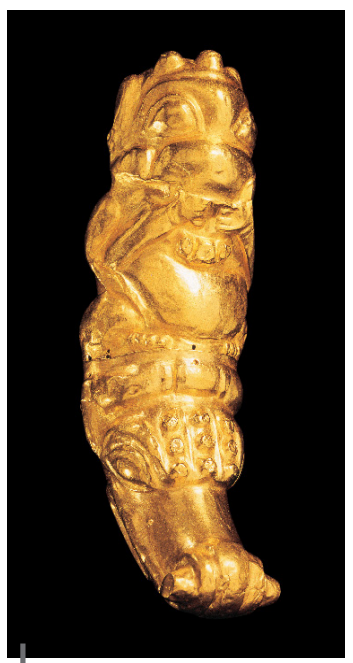

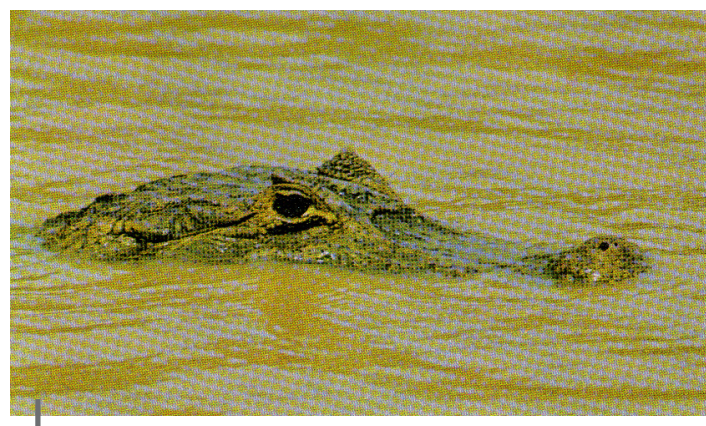

Figura 4. 4 - La posición característica del cocodrilo dentro del agua con todo el cuerpo sumergido menos los ojos y las narices

Fotografía: K. Weidmann

Figura 4. 3 - El mismo motivo en un poporo en oro

Hcda Malagana. Altura 17,2 cm. MO 33338 y 33339.

Colección Museo del Oro, Banco de la República, Bogotá,

Colombia. Fotografía: Rudolf 
Tanto Bouchard \& Mora (1988: 78) como Brezzi (2003: 577, 578) interpretan estas figuras como representaciones de muertos. Brezzi se refiere a ellas como «muerto-caimán» y para él «representa la transmutación de la persona que murió — la actitud recogida y estática así lo sugiere- en caimán, animal del inframundo acuático, de por sí símbolo de muerte. Este motivo puede ser indicio de la existencia de prácticas funerarias que consistieron en la entrega del cadáver a las aguas del río, hábitat de los caimanes». Bouchard y Mora se basan en parte para esta interpretación en los ojos con «órbitas vacías».

Sin tener elementos para descartar del todo esta hipótesis, vale la pena recordar que los ojos perforados no son generalizados en estas piezas y se encuentran en un poco menos de la mitad de la muestra examinada aquí. En el ejemplar ilustrado por Bouchard \& Mora (1988: fig. 104) la perforación grande en el centro del ojo podría representar la pupila, tal vez en estado de dilatación. Se encuentran ojos con perforaciones en algunas otras figuras Tumaco (p.e. Errazuriz, 1980: figs. 114, 115, 117) o en la máscara ilustrada por d'Harcourt (1947: planche LIII, 2) ninguna de las cuales parece representar muertos. En una representación de un cuerpo sin vida podría ser más lógico encontrar ojos simplemente cerrados como los ilustrados en d'Harcourt

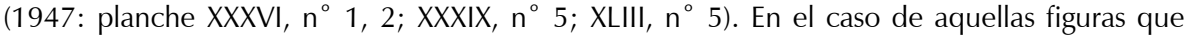
indudablemente representan muertos ya sin ojos, su estado esquelético se nota también en los otros rasgos de la cara (Bouchard \& Mora, 1988: figs. 57, 58). D'Harcourt (1947: 102103) encuentra que ciertos estilos de ojos son característicos o especialmente comunes en determinadas regiones del territorio Tumaco-La Tolita.

La relación exacta entre la figura humana y el cocodrilo es interesante. Mientras que, en la mayoría de los ejemplares, las extremidades de la primera se convierten en el cuerpo y cabeza del segundo, dando pie para la hipótesis de transmutación, en dos ejemplares la figura humana se representa en forma completa con sus pies apoyados sobre la nuca del animal, como si lo estuviera utilizando como medio de transporte. Por los estudios de etnógrafos como ReichelDolmatoff (p.e. 1996: 30), estamos familiarizados con el concepto de la canoa-anaconda, en la cual los tribus tukanos y makús llegaron al Vaupés, pero en algunos mitos se hace referencia a un caimán-canoa. Un mito de los shipibos, por ejemplo, relata la historia de un caimán que es, a la vez, una canoa muy grande que transporta personas de una orilla del río a la otra, un transporte no ausente de peligros porque bajo ciertas circunstancias la canoa se transforma nuevamente en caimán y muerde o mata a sus pasajeros (Roe, 1982: 62-66).

\section{LAS CULTURAS DE LA CORDILLERA OCCIDENTAL - ILAMA}

Dejando atrás los manglares y los anchos ríos de la Costa Pacífica, encontramos el mismo motivo, la figura humana que termina en cabeza de cocodrilo, en las montañas de la Cordillera Occidental de Colombia. En este caso se trata de cuentas de collar de oro de la cultura llama, contemporánea con las fases tempranas de Tumaco (Cardale de Schrimpff et al., 1989). El ejemplar más específico es de la variedad que representa la figura humana de cuerpo entero con los pies apoyados sobre la cabeza del cocodrilo (fig. 4. 2). En vez de la típica cabeza deformada de Tumaco con un tocado que no muestra el pelo, aquí la cabeza es plana y el pelo se indica por una serie de líneas paralelas. Aunque seguramente fue claro para los que hicieron o utilizaron el collar, para nosotros el sexo de la persona es difícil de determinar: a primera vista parece femenina por los senos, pero estos igualmente podrían ser tetillas grandes, mientras lo que se encuentra debajo de los brazos podría ser una representación estilizada de guayuco. El cocodrilo está representado principalmente por una enorme boca llena de dientes y dos ojos grandes ovalados, en la posición natural de los ojos de este animal. Es más estilizado que los ejemplares Tumaco-La Tolita, tal vez debido a que, al darle la forma a la cuenta, primaba la comodidad de esta sobre el realismo, o que el artista no estaba familiarizado con el animal. A 1500 m.s.n.m. el clima de Calima es demasiado frío para el cocodrilo que, en aguas con temperaturas de $18^{\circ} \mathrm{C}$ o menos, se vuelve torpe y se ahoga (Penny, 1991: 100). Por otro lado las tierras bajas 
de la costa son de acceso relativamente fácil desde Calima y hay evidencia de contactos entre la cordillera y el Pacífico, durante prácticamente todo el período precolombino. Además la frontera septentrional de la cultura Tumaco queda en la boca del Río San Juan, distante solo 60 kilómetros en línea recta de Calima (Reichel-Dolmatoff, 1965: 84; Salgado \& Stemper, 1995).

La tercera cultura donde se ha encontrado este estilo de hombre-caimán es Malagana, al oriente de Calima, en el valle ancho y plano del río Cauca. Esta vez se encuentra no en forma de figurina, ni de collar, sino de poporo (fig. 4. 3). Ilustrado en Bray et al. (2005: 162, fig. IV.25), los autores favorecimos la hipótesis de que se trata de una pieza importada de la cultura Tumaco-La Tolita. Sin embargo, después de revisar las otras figuras descritas aquí, esta apreciación parece dudosa. No sería extraño encontrar una pieza así en Tumaco, pero hasta donde se sabe, allá no se conoce en forma de poporo y las diferencias con las figurinas Tumaco son varias. La cabeza del cocodrilo se muestra en forma más naturalista, sin hocico escorzado (cf. fig. 4. 4). La diferencia más notable, sin embargo, está en la figura superior que, en vez de ser explícitamente humana, resulta ser un cocodrilo acurrucado en posición antropomorfa.

El hombre-caimán no es la única representación del cocodrilo conocida de la cultura Ilama. Un collar de oro martillado (Cardale de Schrimpff, 2005: fig. II.41) parece representar cocodrilos en forma bastante natural: tanto el hocico largo como los ojos a los lados de la cabeza insinúan este animal y la posición de las piernas es característica de un cocodrilo en descanso. Una hilera de puntos repujados sobre el lomo podría representar las placas óseas dorsales, mientras las líneas transversales sobre la cola sugieren las bandas horizontales formadas por las placas óseas, bandas acentuadas en algunas especies por colores contrastantes.

En una vasija pequeña (del tipo llamado popularmente «vaso culebrero») se alcanza a reconocer otra representación de cocodrilo, esta vez poco naturalista e íntimamente relacionada con culebras; éstas sustituyen las piernas del animal y cruzan la vasija encima de su cabeza (Cardale de Schrimpff, 2005: fig. II.67). La misma relación se encuentra en un canastero (fig. 5. 1); en este ejemplar la cabeza es más realista (compare la manera de representar la dentadura con la fig. 5. 2) pero el animal está en posición acurrucada como un ser humano16. Aquí, también, culebras sustituyen las piernas y hay otra atravesando la cabeza en la misma posición relativa que se observe en la vasija anterior ${ }^{17}$. Es probable que en el sistema clasificatorio llama, las escamas (de la serpiente) y las placas óseas (cocodrilos) pertenecieran a una misma categoría o a categorías estrechamente relacionadas. El ejemplar de la fig. 5.3 es de interés especial. Al parecer un vaso silbante, lleva modelado en la parte superior un cocodrilo bastante realista con su cola grande y pesada18. Los ojos ovalados, protegidos por una protuberancia ósea pronunciada en forma de arco, están representados de la misma manera que en el canastero y aunque la dentadura con sus grandes colmillos y las fosas nasales altas podría confundirse con la dentadura del murciélago y su hoja nasal, el hocico largo no deja duda de que el animal representado es, en realidad, un cocodrilo19. Sobre la cabeza del animal se observan dos hileras de puntas que recuerdan las que representan las placas óseas en el poporo descrito atrás y, a la vez, los tocados con hileras de puntas encontrados en cierto grupo de canasteros (fig. 5. 4). En una publicación reciente (Cardale de Schrimpff, 2005: 59) sugiero que no solo este tocado hace referencia al cocodrilo, sino que un tipo de collar con dos hileras de rectángulos, usado por algunos canasteros podría representar las escamas de la piel del mismo animal. Si estas hipótesis resultan acertadas, con toda probabilidad el cocodrilo sería un componente del «Ser Fabuloso» de igual importancia que la serpiente, el felino y el murciélago.

\footnotetext{
16 Véase una clasificación de los canasteros en Cardale de Schrimpff, 1989 y 2005.

17 Otro canastero en forma de un cocodrilo estilizado está ilustrado en Cardale de Schrimpff, 2005: fig. II.66.

18 Esta pieza ha sido publicada en varias ocasiones. Legast (1993: fig. 87) comenta que «las manos con el pulgar libre se parecen a las de un primate».

${ }^{19}$ Nachtigall (1961: fig. 435 y p. 145) ilustra una cabeza muy similar en el Museo Arqueológico de la Universidad de Popayán ( $\left.{ }^{\circ} 46.27 .93\right)$ que él identifica como de una babilla.
} 
Figura 5 - El cocodrilo: dentadura y placas óseas

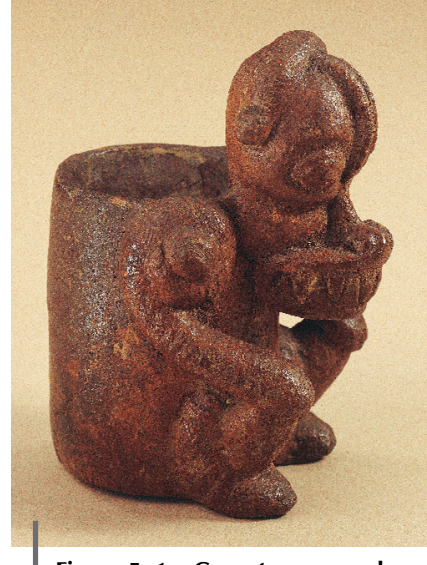

Figura 5. 1 - Canastero con cabeza de cocodrilo y con serpientes que sustituyen sus brazos $y$ piernas

La dentadura se representa en forma bastante realista (cf. fig. 5 . 2). Procedencia indeterminada. Altura: $11,5 \mathrm{~cm}$. ICANH 60A-60. Instituto Colombiano de Antropología e Historia. Fotografía: Rudolf

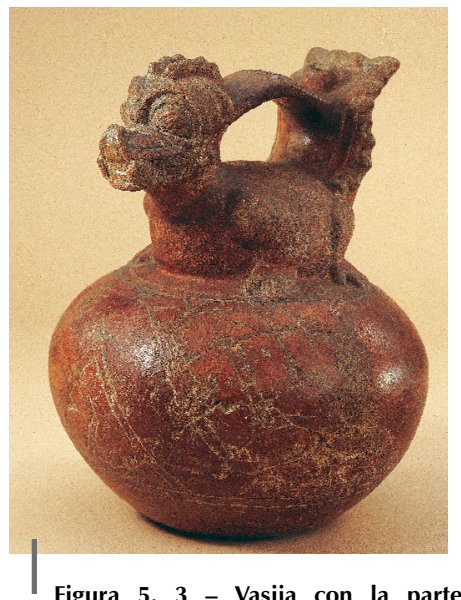

Figura 5. 3 - Vasija con la parte superior modelada en forma de un cocodrilo estilizado

Procedencia indeterminada, pero varios detalles estilísticos sugieren que habría sido elaborada por una cultura relacionada con la llama. Altura: 25,5 cm. ICANH A-67-IV-41. Instituto Colombiano de Antropología e Historia. Fotografía: Rudolf

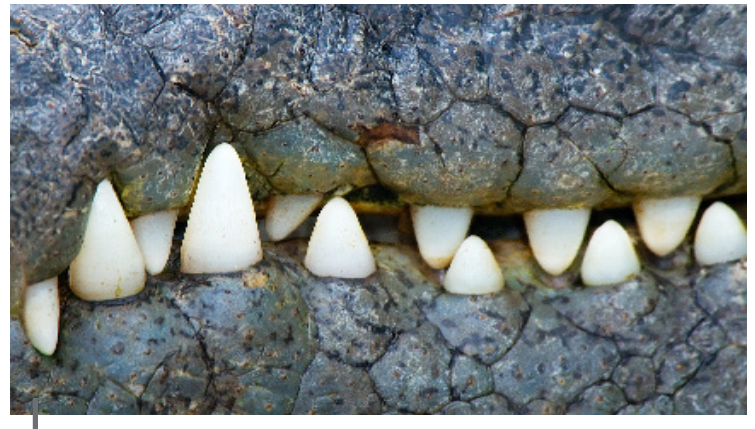

Figura 5. 2 - La dentadura del cocodrilo (Crocodylus acutus) Fotografía: Henry Domke (www. henrydomke.com)

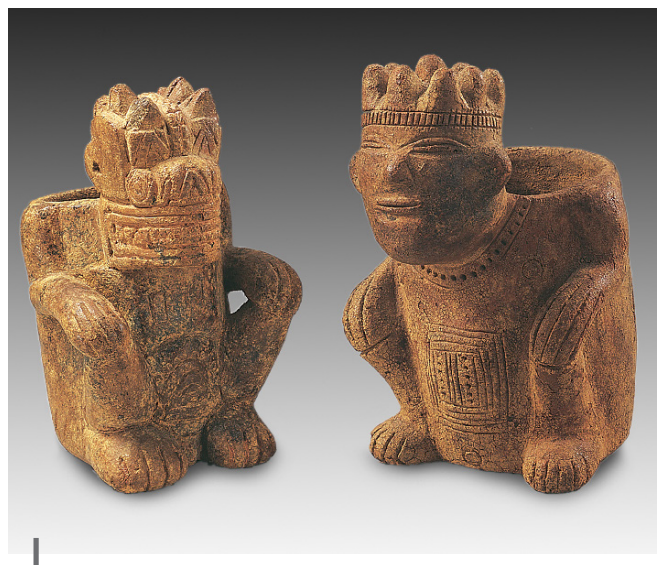

Figura 5. 4 - Canasteros con tocado en puntas

Izq. 12,8 cm, MO CC 6304, Derecho MO 6299. Colección Museo del Oro, Banco de la República, Bogotá, Colombia. Fotografía: Rudolf 


\section{YOTOCO}

En las montañas de Calima la cultura Yotoco se ubica en la cronología inmediatamente después de la Ilama, en contraste con la situación de la planicie del valle del río Cauca donde la presencia Yotoco es restringida y la cultura Malagana ocupa esta posición temporal. Tanto Yotoco como Malagana heredan aspectos importantes de la cultura ancestral, pero con resultados marcadamente diferentes. En contextos Yotoco no se conoce ningún ejemplar de la figura humana que termine en cabeza de cocodrilo como se ha visto tanto en Tumaco como en Ilama y Malagana. En cambio, el cocodrilo se manifiesta principalmente en un estilo de pieza que no se encuentra ni en La Tolita-Tumaco ni en Ilama y que parece ser particular del estilo Yotoco.

Se trata de diademas en lámina de oro de alta ley que llevan, repujada en el centro, lo que Bray (2005: 115) Ilama «La Cara Yotoco». Esta cara, enmarcada por el cabello cortado en forma escalonada, lleva grandes adornos en las orejas y nariz del mismo estilo de las joyas de tamaño natural conocidas de algunas tumbas. Se encuentra en toda una serie de diademas, «pinzas»y pectorales suntuosos. Sin embargo, está asociada con la figura del cocodrilo sólo en las diademas. El Museo del Oro conserva diez ejemplares, la mayoría adquiridos en los primeros años después de su fundación y publicados en detalle por Pérez de Barradas (1954). Aunque tanto el estilo como la poca evidencia disponible indican un origen en la región Calima, la información sobre la procedencia de estas piezas es mínima o está ausente. La parte superior de la diadema está adornada con unas tiras de metal ligeramente curvas que generalmente se interpretan como plumas, tomando en cuenta su forma y el hecho que en los tocados y diademas etnográficas las plumas son un elemento casi indispensable. Debajo de la Cara Yotoco, en una lengüeta, se encuentra generalmente una cara pequeña mientras que en la nariguera de la Cara Yotoco hay una tercera cara, muy estilizada: es decir, además del personaje central parece que hay referencias a dos personajes más.

Los rasgos del cocodrilo se encuentran, no sobre el eje central sino a los dos lados de la pieza. El primer autor en hacer referencia a ellos fue Pérez de Barradas (1954: 125-126, 281) en su estudio magistral sobre la orfebrería Yotoco (que en aquella época llamaba «Estilo Calima»). Él destaca la presencia de figuras de cuerpo entero del cocodrilo en dos de estas piezas: MO 5359 y 5390 (fig. 6. 1). Sin embargo, se propone aquí que las otras diademas son, en realidad, representaciones más fieles del cocodrilo y que los animales de cuerpo entero fueron agregados por un orfebre que quería reforzar el mensaje pero que no tenía ideas muy claras sobre la apariencia del animal.

Los contornos de la parte de la diadema que sale a los dos lados de la Cara Yotoco conforman representaciones bastante fieles del perfil de un cocodrilo. Uno de los rasgos más importantes del hocico es la nariz elevada que permite al animal respirar aun cuando todo el resto del cuerpo se encuentra sumergido bajo el agua (fig. 4. 4). Esta es la posición en la que el cocodrilo pasa largas horas al día y es esencial para su estrategia de cacería, permitiéndole pasar desapercibido mientras asecha su presa. Al final del hocico largo y lleno de dientes, se encuentran los ojos redondos, protegidos por una cresta ósea gruesa. Este perfil se encuentra en todas las siete diademas de este estilo. Los dientes se representan de distintas maneras, siendo una hilera de triángulos la más naturalista (M.O. 5202 y 5360, fig. 6. 2, comparar con fig. 5. 2). En los dos ejemplares que muestran el cuerpo entero del cocodrilo, los dientes son dos hileras cortas de rectángulos mientras que en otras diademas, son tan estilizados que difícilmente se reconocerían como tal si no fuera por las líneas horizontales que los bordean, demarcando los límites del hocico. En algunos ejemplares se indica la piel con escamas por medio de un achurado romboidal. Este, nuevamente, es el caso de los cocodrilos de cuerpo entero como también en el M.O. 5202.

En tres de los ejemplares ( ${ }^{\circ}$ M.O. 4297, 5202 y 5360) el orfebre parece haber reinterpretado la nariz elevada de la cabeza del cocodrilo como el pico de un pájaro con ojo grande. Pérez de Barradas, incluso, comenta (1954: 242), para el caso del MO 4297, que «...sugieren las imágenes de dos loros o guacamayos. La representación de la cabeza es clara, pues tiene el pico 
Figura 6 - El cocodrilo con elementos de ave y figuras con piel de cocodrilo

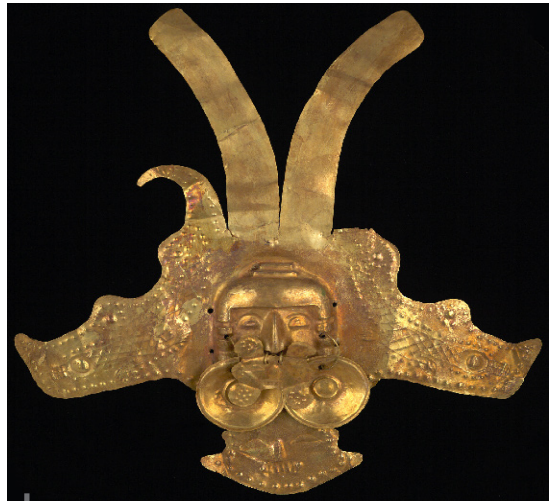

Figura 6. 1 - Diadema Yotoco

Procedencia: indeterminada. 22,5 x 23,3. MO 5359. Colección Museo del Oro, Banco de la República, Bogotá, Colombia

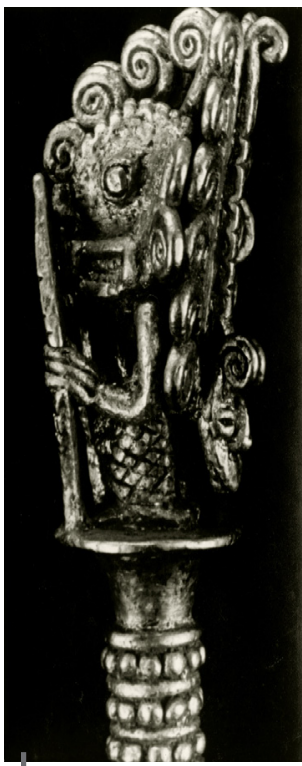

Figura 6. 3 - Palillo para la cal que termina en una figura antropomorfa con máscara de murciélago. La figura lleva un cocodrilo sobre la espalda

Procedencia: ¿Restrepo? Altura de la figura: 2,9 cm. MO 5235. Colección Museo del Oro, Banco de la República, Bogotá, Colombia. Foto: J. M. Munera

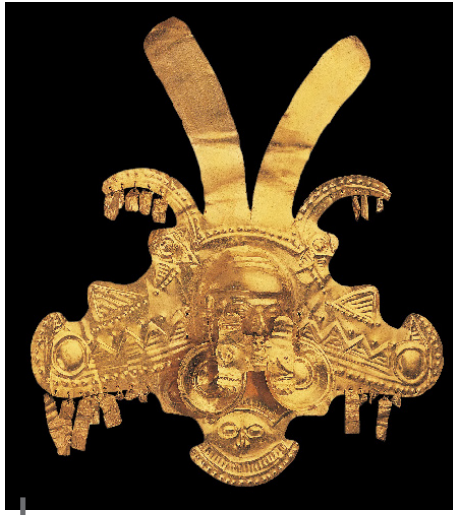

Figura 6. 2 - Diadema Yotoco

Procedencia: Restrepo. $26 \times 27 \mathrm{~cm}$ MO 5202. Colección Museo del Oro, Banco de la República, Bogotá, Colombia. Foto: Rudolf

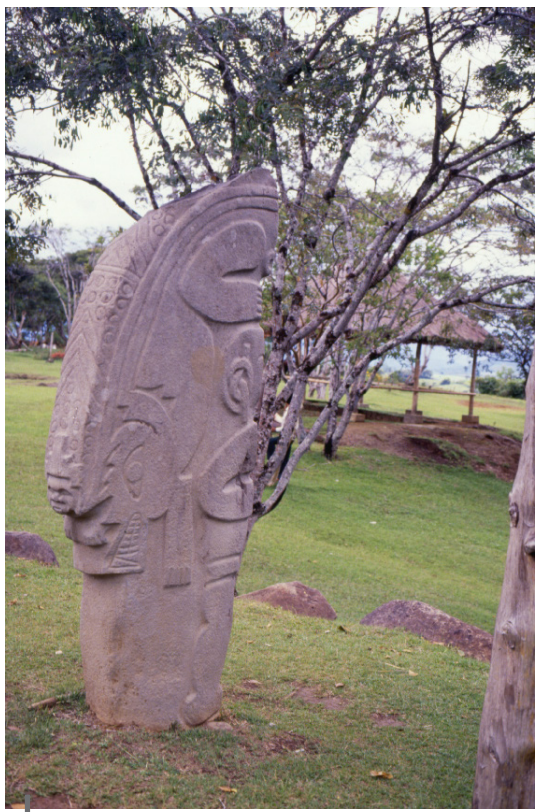

Figura 6. 4 - Estatua, Alto de las Piedras, San Agustín, Huila

Parece representar una figura humana vistiendo una «capa» de piel de cocodrilo. Foto de la autora 
dirigido hacia arriba, y el ojo está representado por un círculo rodeado de una línea, ambos realzados. La cabeza está separada del cuerpo por una línea vertical...». Sin embargo, el orfebre no parece haber desconocido la presencia del cocodrilo, puesto que dos de estos ejemplares son precisamente los que tienen los dientes de este animal representados en la forma más naturalista y, en uno de los casos (M.O. 5202), se observa el achurado que representa las escamas o las placas óseas (fig. 6. 2). Este grupo de diademas tiene algunos otros rasgos particulares en común, como una hilera de colgantes sobre cada una de las «plumas» laterales y (en dos de los tres casos) una lengüeta, otra vez con cara estilizada, que reemplaza las plumas centrales.

La asociación entre las tres especies (hombre, ave y cocodrilo) en esta pieza es, a primera vista, sorprendente. El ser humano con diadema de plumas es un motivo con el cual estamos familiarizados, pero la asociación entre ave y cocodrilo requiere de mayor explicación. Las primeras vuelan, cantan, están cubiertas de plumas; los segundos nadan, su mundo predilecto es el agua y están cubiertos de escamas y placas óseas. Sin embargo, en el mundo precolombino los animales se clasificaron de una manera muy diferente a la del mundo occidental. Para las personas que elaboraron y usaron estas piezas, los rasgos importantes, tal vez, no eran ni plumas ni escamas, sino el hecho de que tanto el cocodrilo como las aves hacen nidos y ponen huevos. Por otro lado, las aves tienen escamas sobre las piernas y, en muchas especies de serpiente, las formas de las escamas y su posición traslapada sobre el cuerpo sorprende por su parecida con las plumas. El concepto de una relación entre plumas y escamas estaría ejemplificado en la serpiente emplumada. Más aun, las aves cambian de plumas y los cocodrilos de piel, característica que comparten con insectos, algunos de los cuales también vuelan.

Tanto las aves como los cocodrilos comparten la característica de vivir en dos elementos: las primeras habitan la tierra y el aire y los otros, la tierra y el agua. Más aun, en muchas cosmologías indígenas el cielo, durante la noche, se transforma en el inframundo y el inframundo, a la vez, se convierte en el cielo20. Una extensión lógica de este concepto podría ser que los habitantes de cada mundo también sufren un cambio, según el cual los habitantes del agua (como peces y cocodrilos) se convierten, por la duración de la noche, en aves y otros habitantes del firmamento, mientras éstos se vuelven animales del agua. Aun así, la hipótesis de una relación entre las dos familias, y de un ser en la cosmología Yotoco que combina aspectos de ave con cocodrilo podría parecer demasiado atrevida. Sin embargo, la cultura Yotoco no es la única del suroccidente colombiano donde se encuentra esta asociación: en una figura encontrada en la hacienda Malagana también están plasmados aspectos de las dos familias (fig. 7).
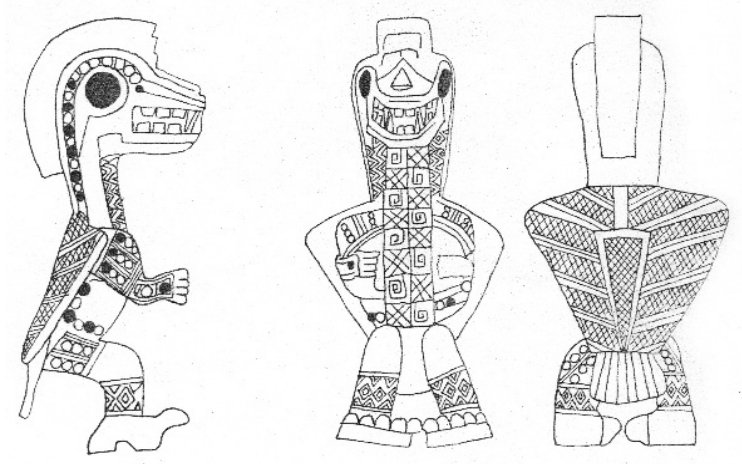

Figura 7 - Ser mítico que combina la cabeza de un cocodrilo con el cuerpo y alas de un ave $y$ manos y pies humanos

Hcda Malagana. Altura: $11,9 \mathrm{~cm}$. Reproducido de Legast (1998) con el permiso de la autora

20 Acerca de la relación entre ave y cocodrilo agradezco las sugerencias de Stephen Hugh-Jones en quien se originen muchas de las ideas expresadas aquí. 
Estas piezas no son la única referencia Yotoco al cocodrilo. Un poporo elaborado en lámina de oro (MO 5274; Pérez de Barradas, 1954: lam 92) ha sido interpretado por Legast (1993: 43) como una babilla. En el caso de los remates de los palillos para la cal, varias de las figuras humanas llevan un achurado sobre las piernas que probablemente represente la piel de serpiente tal como se representaba anteriormente en Ilama. Sin embargo, en algunos casos las figuras llevan prendas en forma de pantalón corto con rectángulos incisos, posiblemente la representación de las escamas del cocodrilo (p.e. Pérez de Barradas, 1954: lam. 79). Varias de estas piezas llevan una figura de animal en posición antropomorfa, identificado generalmente como un murciélago que sostiene una serpiente en las manos o las garras delanteras (p.e. Legast, 1993: 96, figs. 98100). Una de estas figuras (fig. 6. 3; MO 5235) lleva, en la espalda, una figura de cocodrilo21 que, hasta cierto punto, recuerda la estatua del Alto de las Piedras (San Agustín), descrita más adelante e interpretada como un chamán que lleva puesta una piel de cocodrilo.

\section{TIERRADENTRO Y SAN AGUSTÍN}

El Museo del Oro conserva dos piezas de la región de Tierradentro con representaciones del cocodrilo muy diferentes entre sí: un pectoral y un dije. El pectoral es plano, de oro martillado; su forma, alargada con dos protuberancias curvas en la parte superior y un motivo repujado en el centro, es común en el suroccidente de Colombia durante los últimos siglos antes de Cristo y los primeros después, donde cada sociedad le imprimía su estilo particular (Bray et al., 2005: fig. IV.35). Este ejemplar lleva un cocodrilo bastante realista, con varias hileras de placas óseas a lo largo del lomo y una línea repujada cerca de los ojos, que parece representar la arruga interocular característica de la babilla. La cola termina en un diseño geométrico abstracto. El dije, en cambio, es una pieza fundida grande. Es relativamente naturalista, pero la boca no parece tener una dentadura acentuada, lo cual deja en entredicho su identificación como cocodrilo. Por otro lado, dos hileras de protuberancias rectangulares sobre el lomo parecen representar las hileras de placas óseas tan características de este animal.

En su estudio pionero sobre las representaciones precolombinas del cocodrilo, Medem (1953: 12-14) identifica tres ejemplares en las estatuas de San Agustín22. Uno de ellos es una estatuacolumna publicada por Preuss (1929: tomo II, lam. 18, 1 y fig. 5, 1-3) sobre la cual se apoya parte del techo del templete del montículo oriental de la Meseta A (costado norte). El guerrero tallado en esta estatua 23 lleva encima un animal con una cabeza en cada extremo. La parte trasera y lateral de la estatua está ocupada por el cuerpo del animal que se adelgaza y enrosca como una serpiente para terminar «...en una cabeza de cocodrilo muy estilizada; esta muestra una nariz curva hacia arriba, colmillos muy largos en las mandíbulas superior e inferior y entre los ojos, una protuberancia que presenta en su extremo una formación engrosada, semi-circular». La cabeza del otro extremo es esculpida en vez de ser tallada en bajo relieve pero, en mi concepto, es del mismo animal en una versión escorzada24. Los rombos, bordeados a cada lado por una hilera de rectángulos, que se encuentran sobre la primera parte del cuerpo del animal, representarían las placas óseas. Es interesante constatar que estas hileras de rectángulos, ausentes en la parte del cuerpo serpentiforme (que lleva el achurado romboidal característico de las representaciones de culebras), aparecen de nuevo cerca de la cabeza del otro extremo. Los artistas precolombinos no

\footnotetext{
21 Una fotografía excelente de esta pieza fue publicada por Pérez de Barradas (1954: lam. 85).

22 No todos los investigadores posteriores están de acuerdo con esta identificación. Reichel-Dolmatoff, por ejemplo (1972: 108-109) considera que el animal montado en la figura humana en la estatua del Alto de las Piedras es un jaguar.

23 Esta estatua tiene una compañera muy similar pero Medem solo describe una de ellas; para la segunda estatua ver Preuss (1929: tomo II, lam. 18-2 y lam. 19, 3-4).

24 Preuss, en cambio (1929: 27), considera que el animal representado es un mico.
} 
solo eran conscientes de las similitudes entre las escamas de los cocodrilos y las de las serpientes pero, a la vez, sabían muy bien diferenciarlas.

Una segunda figura, de la orilla occidental del Río Lavapatas, lleva a cuestas un animal de cabeza doble (Preuss, 1929: tomo II, lam. 49, 1-3, figs. 27, a-b) que se parece en varios aspectos a las figuras anteriores. La primera cabeza se encuentra colocada «a manera de gorra» sobre la cabeza del hombre y Medem plantea que puede tratarse de un jaguar o puma. No cabe duda de que el animal que cuelga detrás es un cocodrilo con una cresta dorsal muy alta, adornada con incisiones. Medem (1953: 13) considera que la estatua podría representar un personaje cubierto con una piel. La literatura etnográfica abunda en referencias a chamanes vistiéndose con pieles de jaguar (p.e. Reichel-Dolmatoff, 1975) pero no sería nada raro, si el cocodrilo también jugó un papel importante en la cosmología, que los chamanes de la época se hubieran cubierto con pieles de cocodrilo. Para los tukanos, el caimán y el jaguar se clasifican en la misma categoría de «predador grande, feroz, terrible» (Stephen Hugh-Jones, comunicación personal, 2006).

La tercera figura, del Alto de las Piedras (fig. 6. 4)25, es casi idéntica a la anterior con la sola diferencia que «el hocico del cocodrilo es menos curvo y la cresta dorsal muestra fuera de las incisiones, círculos en alto relieve» (Medem, 1953: 14). En varias de las figuraciones de cocodrilos descritas en este artículo las placas óseas están representadas por círculos y es posible que la forma de alternarlos aquí con las incisiones trate de imitar las bandas del dorso y cola de los animales jóvenes. Medem agrega (1953: 16) que debido a la altura de San Agustín (1 600 m.s.n.m.) no existen crocodilos en sus alrededores

«pero en cambio los hay en las regiones situadas más al sur del Huila, y en la parte superior del [valle del] Río Magdalena, por lo tanto, los antiguos constructores de los adoratorios en San Agustín debieron haber conocido los cocodrilos no del territorio donde hoy se hallan las estatuas, sino de otros parajes distantes».

Hoy se sabe, gracias a las investigaciones de Hector Llanos (1993), que el territorio de los constructores de San Agustín se extendía hasta el municipio de Garzón en el departamento del Huila, incorporando precisamente los territorios que menciona Medem.

\section{CONCLUSIONES}

En su interesantísimo estudio sobre los animales en el Ecuador prehispánico, Andrés Gutiérrez Usillos (2002: 69) resume la hipótesis de Presley Norton con la cual parece estar de acuerdo. Propone que mientras las formas faunísticas más frecuentes en la iconografía Chorrera son «el águila arpía, el felino, el caimán y la serpiente equis», posteriormente se van sobreponiendo las representaciones de otras especies. Estas «irán tomando cierta preponderancia en el acervo mítico de las culturas ecuatorianas y mesoamericanas y... se constituirán en "divinidades" menores, más próximas en la actividad cotidiana que los arcanos dioses mayores constituidos por el caimán, o el jaguar...».

Este artículo demuestra, sin embargo, que el cocodrilo (sea C. acutus, sea babilla o sean las dos) seguía teniendo una importancia considerable durante el período de nuestro estudio, después del fin de la cultura Chorrera, tanto en el suroccidente de Colombia como en las regiones vecinas del Ecuador. Inclusive, tal vez era más importante que antes (fig. 2). Sin embargo, las representaciones de estos animales o las referencias a ellos no son siempre fáciles de detectar. Hemos destacado algunos de los rasgos diagnósticos que parecen haber tenido especial importancia para el artista precolombino: un hocico muy largo terminando en una nariz abultada y a una altura mayor; dentadura poderosa con colmillos grandes, a veces con la apariencia "desordenada" característica de la babilla, ojos alargados protegidos por un arco óseo y, también, escamas y placas óseas representadas de manera natural, o estilizada en forma una cresta o tocado.

\footnotetext{
25 Ver, también, Preuss 1929: tomo II, lam. 73.
} 
Se han podido detectar cuatro grandes temas, todos los cuales se encuentran en más de una de las sociedades precolombinas del suroccidente colombiano o sea que trascendían la cosmología local:

- El primero de estos temas, el hombre-caimán, se encuentra a ambos lados de la frontera actual, en Tumaco-La Tolita, además de Ilama y Malagana (fig. 4).

- Un segundo tema es la presencia, al parecer importante, del cocodrilo como un componente del Ser Fabuloso llama, explícita en algunos canasteros y, probablemente, implícita en otras (fig. 5). El canastero es, desde luego, una forma importante en Tumaco-La Tolita y el tocado que se interpreta como una representación de las placas óseas también se encuentra en algunas figurinas de esta cultura (Brezzi, 2003: fig. 524). Sin embargo, la posible extensión de este tema a Tumaco-La Tolita es una hipótesis que requiere de más investigación.

- El tercer tema es el cocodrilo asociado con elementos de ave y de ser humano, que se encuentra en cierto estilo de diadema Yotoco y en una pieza muy especial encontrada en Malagana (figs. 6 y 7 ).

- Por último tenemos la representación de un ser humano que, al parecer, lleva puesta la piel de un cocodrilo para poder, de esta manera, asumir las cualidades y poderes de este animal (figs. 6.3 y 6. 4). Este tema se encuentra en algunas estatuas de San Agustín y también, al parecer, sobre el remate de un palillo para la cal de la cultura Yotoco. Sin embargo, es posible que ponerse su piel no fuese la única manera de adquirir las cualidades del animal. Llama la atención la presencia, en Tumaco-La Tolita, de diversos objetos de indumentaria como narigueras y cuentas de collar con forma de cocodrilo, que tal vez también ayudaban a conferir las cualidades de este animal. De igual importancia habría sido la pintura corporal ejecutada con pintaderas. Entre los Emberas actuales de la región del Chocó, el Jaibaná se pinta el cuerpo con el diseño del tigre y de esta manera asume la naturaleza del animal cada vez que quiere (Ulloa 1992: 227). Posiblemente los de Tumaco-La Tolita habrían utilizado la pintadera con cabeza de cocodrilo, ilustrada en la figura 2.3, para fines similares. En palabras del etnólogo Viveiros de Castro (1998: 482)

«La ropa de animales que utilizan los chamanes para viajar en el cosmos son instrumentos y no adornos de fantasía; tienen una función similar al equipo de buceo o al traje espacial y no a la máscara de carnaval. La intención, al ponerse un traje de buzo, es de lograr funcionar como un pez, de poder respirar por debajo del agua...».

Agrega «El poner ropa en forma de máscara... se hace para activar los poderes de un cuerpo diferente»26. En este orden de ideas, la máscara de cocodrilo utilizada por el canastero llama (fig. 5. 1) tendría una función similar a la de la piel. Otras figuras Ilama, sin embargo, parecen más una referencia a un ser mítico o divino que comparta aspectos humanos con los del cocodrilo y muchos otros animales, un ser que viene a ser, tal vez, el ancestro de una deidad Yotoco y Malagana (figs. 6. 1, 6. 2 y 7) cuya esencia humana se comparta con elementos del cocodrilo y del ave, permitiéndole dominar los tres elementos de tierra, agua y aire.

En el Ecuador, también, el cocodrilo era, indudablemente, de importancia en la cosmología de las sociedades del período Desarrollo Regional; a principios de este artículo se examinaron las representaciones del cocodrilo en Chorrera y en La Tolita-Tumaco pero no se alcanzó a seguirle la pista en forma más amplia. Sin embargo, parece probable que las representaciones sí existan y sería muy interesante buscar, en el Ecuador, los diferentes íconos que se han descrito para el suroccidente de Colombia. Al igual que en Colombia, habrá que estar atento a representaciones que muestran solamente parte del cocodrilo o elementos de este mezclados con elementos característicos de otros animales formando seres compuestos o fabulosos. Un ejemplar interesante de un ser compuesto de este tipo está representado sobre, por al menos, dos piezas muy similares en el Museo del Banco Central ( $N^{\circ}$ MCBQ 1-55-77, ilustrado Valdés, 1992: fig. 
72 y $\mathrm{n}^{\circ}$ 1-51-77, ilustrado en Équateur, 1991: 74). Se trata de recipientes de cerámica JamaCoaque en los cuales la serpiente se reconoce fácilmente mientras los miembros del animal, que terminan en garras, podrían ser de un felino. En la cabeza la nariz «respingada» recuerda, a primera vista, la hoja nasal del murciélago pero parece más probable que esta forma, combinada con la manera de representar la dentadura, represente el hocico del cocodrilo. La forma de los ojos es igual a la que se utilizaba en muchas representaciones naturalistas de cocodrilos y la cresta detrás podría representar las placas óseas de este animal.

\section{Agradecimientos}

Varias personas leyeron versiones preliminares del manuscrito e hicieron valiosos comentarios desde el punto de vista de sus diferentes especializaciones: Warwick Bray, Leonor Herrera, Marta Herrera, Stephen HughJones, Anne Legast, Clemencia Plazas y Laura Quintero. Ellas así como otras me enviaron ilustraciones de cocodrilos para las cuales agradezco también a Karen Bruhns y, del Museo del Oro, Alba Luz Gómez, Juanita Sáenz Obregón, Juanita Sáenz Samper y Clark Manuel Rodríguez. Para su generoso permiso de utilizar sus fotografías de animales vivos, agradezco a Henry Domke y Karl Weidmann.

\section{Referencias citadas}

BOUCHARD, F. \& MORA, S., 1988 - Cultura Tumaco. Arte de la Tierra, 84 p.; Bogotá: Fondo de Promoción de la Cultura, Banco Popular. Colección Tesoros Precolombinos.

BRAY, W., CARDALE de SCHRIMPFF, M., HERRERA, L., LEGAST, A., PATIÑO, D. \& RODRÍGUEZ, C.A., 2005 - Lords of the Marshes: the Malagana People. In: Calima and Malagana. Art and Archaeology in Southwestern Colombia (Marianne Cardale de Schrimpff ed.): 140201; Bogotá-Lausanne, Pro Calima.

BREZZI, A., 2003 - Tulato. Ventana a la prehistoria de América. Cultura Tumaco-La Tolita, 621 p.; Bogotá: Villegas Editores.

CADENA, A. \& BOUCHARD, J.-F., 1980 - Las figurillas zoomorfas de cerámica del litoral pacífico ecuatorial. Bulletin de I'Institut Français d'Études Andines, IX (3-4): 49-68.

CARDALE DE SCHRIMPFF, M., 1984 - Techniques of Hand-weaving and allied Arts in Colombia, 2 vols., 701 p., 131 figs., 337 fotos; Ann Arbor: University Microfilms International.

CARDALE DE SCHRIMPFF, M., 1989 - The Snake and the Fabulous Beast: themes from the pottery of the Ilama culture. In: Animals into Art (H. Morphy ed.): 75-106; WellingtonLondon-Boston-Sydney: One World Archaeology. Unwin Hyman.

CARDALE DE SCHRIMPFF, M. (ed.), 2005 - Calima and Malagana. Art and Archaeology in Southwestern Colombia, 304 p.; Bogotá-Lausanne: Pro Calima.

CARDALE DE SCHRIMPFF, M., BRAY, W. \& HERRERA, L., 1989 - Ornamentos y máscaras de oro de la cultura llama. Metalurgia del período formativo tardío en la cordillera Occidental Colombiana. Boletín del Museo del Oro, 24: 55-71.

ÉQUATEUR., 1991 - La Terre de L'Or, 138 p.; Lausanne: Fondation de L’Hermitage. Catálogo de la exposición de este nombre, octubre 1991-enero 1992.

ERRÁZURIZ, J., 1980 - Tumaco-La Tolita, una cultura precolombina desconocida, 316 p.; Bogotá: Carlos Valencia Editores.

GUTIÉRREZ, A., 2002 - Dioses, Símbolos y alimentación en los Andes. Interrelación hombrefauna en el Ecuador prehispánico, 473 p.; Quito: Ediciones Abya-Yala.

D'HARCOURT, R., 1947 [1942] - Archéologie de la Province d'Esmeraldas (Équateur). Journal de la Société des Américanistes, nouvelle serie, tome XXXIV: 60-200; París: Musée de I'Homme. 
LATHRAP, D., 1995 - El Ecuador Antiguo. Cultura, Cerámica y Creatividad, 3000-300 A.C., 110 p.; Chicago-Guayaquil: Field Museum of Natural History.

LEGAST, A., 1991 - El felino en San Agustín. In: San Agustín, 200 años, 1790-1990: 41-47; Bogotá: Fundación de Investigaciones Arqueológicas Nacionales.

LEGAST, A., 1993 - La fauna en el material precolombino Calima, 115 p.; Bogotá: Fundación de Investigaciones Arqueológicas Nacionales.

LEGAST, A., 1995 - Iconografía del suroccidente de Colombia. In: Perspectivas Regionales en la Arqueología del Suroccidente de Colombia y Norte del Ecuador (C. Gnecco, ed.): 263297; Popayán: Editorial Universidad del Cauca.

LEGAST, A., 1998 - Los símbolos animales de Malagana. Boletín de Arqueología Fundación de Investigaciones Arqueológicas Nacionales, 10 (3): 3-79; FIAN.

LLANOS, H., 1993 - Presencia de la cultura de San Agustín en la depresión del valle del río Magdalena, Garzón-Huila, 99 p.; Bogotá: Fundación de Investigaciones Arqueológicas Nacionales.

MEDEM, F., 1953 -El cocodrilo. Estudio inicial sobre las representaciones zoomorfas precolombinas en el arte indígena de Colombia, 92 p.; Bogotá: Imprenta del Banco de la República.

MEDEM, F., 1981- Los crocodylia de sur America. Vol. I: los crocodylia de Colombia, 354 p.; Bogotá: Universidad Nacional de Colombia-Colciencias.

MEDEM, F., 1983 - Los crocodylia de sur America. Vol. II: los crocodylia de sur América, 271 p.; Bogotá: Universidad Nacional de Colombia-Colciencias.

MILLER, M. \& TAUBE, K., 1997 - The Gods and Symbols of Ancient Mexico and the Maya. An illustrated dictionary of Mesoamerican religion, 216 p.; Londres: Thames and Hudson.

NACHTIGALL, H., 1961 - Indianerkunst der Nord-Anden, 250 p.; Berlin: Dietrich Reimer Verlag.

PENNY, M., 1991 - Alligators and Crocodiles, 128 p.; London: Boxtree.

PÉREZ DE BARRADAS, J., 1954 - Orfebrería prehispánica de Colombia. Estilo Calima, 2 vols., 367 p. + 300 láminas; Madrid: Talleres gráficos JURA.

PREUSS, T., 1929 - Monumentale Vorgeschichtliche Kunst. Ausgrabungen im Quellgebiet des Magdalena in Kolumbien und ihre Ausstrahlungen in Amerika, 2 Tomos, 106 p. +87 láminas y 193 figuras; Göttingen: Vandenhoeck \& Ruprecht.

RAMÍREZ GUARÍN, A. L., 2003 - El concepto de estilo en arqueología. Análisis estilístico de figurinas antropomorfas Tumaco-La Tolita: un estudio de caso; Bogotá: Museo Arqueológico Casa del Marqués de San Jorge. Monografía para optar al título de Antropólogo, Departamento de Antropología, Universidad Nacional de Colombia, Bogotá.

REICHEL-DOLMATOFF, G., 1965 - Colombia. Ancient Peoples and Places Series, 231 p.; London: Thames and Hudson.

REICHEL-DOLMATOFF, G., 1972 - San Agustín. A culture of Colombia. Art and Civilization of Indian America series, 163 p.; London: General Editor Michael Coe. Thames and Hudson.

REICHEL-DOLMATOFF, G., 1975 - The Shaman and the Jaguar. A Study of Narcotic Drugs among the Indians of Colombia, 280 p.; Philadelphia: Temple University Press.

REICHEL-DOLMATOFF, G., 1996 - The Forest Within. The World-View of the Tukano Amazonian Indians, 229 p.; Themis Books: Totnes.

RODRÍGUEZ, E. E,. 1992 - Fauna precolombina de Nariño, 115 p.; Bogotá: Fundación de Investigaciones Arqueológicas Nacionales.

ROE, P.G., 1982 - The Cosmic Zygote. Cosmology in the Amazon Basin, 384 p.; New Brunswick, New Jersey: Rutgers University Press.

SALGADO, H. \& STEMPER, D., 1995 - Cambios en Alfarería y Agricultura en el Centro del Litoral Pacífico Colombiano durante los dos últimos milenios, 234 p.; Bogotá: Fundación de Investigaciones Arqueológicas Nacionales, Banco de la República.

SÁNCHEZ MONTAÑÉS, E., 1981 - Las «Figurillas» de Esmeraldas: Tipología y Función, 158 p.; Madrid: Ministerio de Asuntos Exteriores, Dirección General de Relaciones Culturales. 
EL cocodrilo en el suroeste de Colombia y regiones vecinas del Ecuador (800 a. C. a 500 d. C.)

SIMON, Fray P., 1981 [1627] - Noticias Historiales de la Conquista de Tierra Firme en las Indias Occidentales, 5 tomos; Bogotá: Biblioteca del Banco Popular.

ULLOA, A., 1992 - Kipará. Dibujo y Pintura. Dos formas EMBERA de representar el mundo, 350 p.; Bogotá: Centro Editorial Universidad Nacional.

VALDÉS, F., 1992 - La tradición cerámica La Tolita. In: Signos Amerindios, 5000 Años de Arte Precolombino en el Ecuador (Francisco Valdez \& Diego Veintemilla eds.): 135-165; Quito: Ediciones Colibri.

VIVEIROS DE CASTRO, E., 1998 - Cosmological Deixis and Amerindian Perspectivas. The Journal of the Royal Anthropological Institute, Vol. 4, $\mathbf{n}^{\circ}$ 3: 469-488; Londres. 